Portland State University

PDXScholar

$5-26-2017$

\title{
Learning Assessment of Accuracy of Learning between Musicians and Nonmusicians
}

\author{
Emily M. Drapela \\ Portland State University
}

Follow this and additional works at: https://pdxscholar.library.pdx.edu/honorstheses

\section{Let us know how access to this document benefits you.}

\section{Recommended Citation}

Drapela, Emily M., "Learning Assessment of Accuracy of Learning between Musicians and Nonmusicians" (2017). University Honors Theses. Paper 410.

https://doi.org/10.15760/honors.409

This Thesis is brought to you for free and open access. It has been accepted for inclusion in University Honors Theses by an authorized administrator of PDXScholar. Please contact us if we can make this document more accessible: pdxscholar@pdx.edu. 
Learning Assessment of Accuracy of Learning between Musicians and Nonmusicians

by

\section{Emily Drapela}

An undergraduate honors thesis submitted in partial fulfillment of the

requirements for the degree of

Bachelor of Science

in

University Honors

and

Speech and Hearing Science

Thesis Adviser

Dr. Sarah Key-DeLyria

Portland State University 


\section{ABSTRACT}

The relationship between music and brain physiological changes have been explored extensively (Fields, 2011; François, Grau-Sánchez, Duarte, \& Rodriguez-Fornells, 2015). Research has identified how music has played a positive role in recovery from traumatic brain injury (Baker, Wigram, \& Gold, 2005; Francois, \& Schon, 2011), learning different languages (Creech 2008), and refining skills (Creech 2008). However, there has been a lack of research regarding the relationship between music and the accuracy of learning. In this study, we have performed an assessment of learning comparing five college-age musicians and five college-age nonmusicians. We did not find a significant difference between groups, perhaps due to the small sample size, the lack of specificity in type of instrumentation, or specific musical experience characteristics. Results are discussed with regard to the literature on musical training, sight reading ability, instrument specific literature and learning ability.

\section{KEY WORDS}

Myelination, Synapses, Neurons, Short-term memory, Learning, Gray matter 


\section{INTRODUCTION}

It was once thought that when we reach a certain age we no longer make new neurons. On the contrary, Sherman (2015) argues that there is now growing evidence that we need new neurons to learn and this is driven by intellectually stimulating material. This happens in the ventricles and hippocampus over the lifespan (Wan, \& Schlaug, 2010,). Developing new neurons and learning related changes to neurons is termed neuroplasticity (Strait \& Kraus, 2014). Musicians may have additional advantages in neuroplasticity (Wan, \& Schlaug, 2010).

\section{Musical Training and Neuroplasticity}

Music training is a complex process that involves many structures in the brain. The neurology of music training involves "auditory pathways, other specified regions, Heschl's gyrus, the planum temporale," (Newton 2015). As the instrumentalist is training on their instrument, they are sensitive to the auditory feedback. They are analyzing pitch, making adjustments, creating emotional responses, and memorizing details. This happens over a very short timespan. This is significant because music training is a combination of attention to auditory sensitivity and memory, and these abilities are related to the neurology of motor and visual training.

Motor training is believed to change white matter within the brain (Schmithorst \& Wilke, 2002). During typical childhood development, white matter growth has been associated with fine motor movement ability. (Schmithorst \& Wilke, 2002). Authors Schmithorst and Wilke (2002) use diffusion anisotropy to show changes in white matter. Activation of the corpus callosum and planum temporale over time were found to have increased white matter too (Schmithorst \& Wilke, 2002). Children and young adults who began musical training during brain development have been shown to have anatomically changed gray matter and white matter (Gaser \& Schlaug, 
2013). It is known that when playing a musical instrument, heavy repetition and sequencing is involved with finger and breath coordination, stimulating the cerebellum and striatum. Additional studies have been able to investigate the relationship between the cerebellum and striatum and have found that both brain structures play a key role in repetitive complex motor movements (Shadmehr, \& Holcomb, 1997). Thus, research has shown that an increase in myelination increases the rate of transmission of nerve impulses, and is therefore a possible explanation for high level musician ability (Bengtsson et al., 2005).

Musicians have demonstrated enhanced motor and sensory learning capabilities (Gaser \& Schlaug, 2013). Musicians, sight-reading, performance, and practice is all dependent on finger and hand movements. Gaser and Schlaug have found that musicians who practiced at least 1 hour per day had increased gray matter in the primary motor and somatosensory regions of the brain. These locations in the brain are associated with motor movement such as planning, preparation, and execution of finger movements. This study further suggests that neural plasticity encourages an increase in gray matter and makes it easier for musicians brain structures to adapt to ever changing environments. Gaser and Schlaug quoted a study in which animals performed continuous motor training and displayed neural plasticity and changes in the hippocampus, ventricles and cerebellum (as cited in Anderson, 1994). They found a significant increase in synapses and glial cells in the cerebellar cortex. This is significant because with this increase in brain activity and structure, studies have found musicians to have better long-term memory, benefits in language processing, and improvements in cognitive processing (Dittinger et al., 2016). Thus, there is a connection between gray matter increases growth and musical training. Practicing music has specific effects on the human brain. For example, musicians may have more synapses than nonmusicians due to the challenge of learning new pieces of music. It 
is the combination of sensory and motor learning and memory that promotes the creation of new synapses, neurons, and myelination (Bednarek \& Caroni, 2011). In a study conducted by Bednarek and Caroni, mice were used to study the effect of environmental sensory enrichment and the formation of new synapses as well as the reformation of preexisting synapses and neurons. They found an increase in synapses and enhanced plasticity. Music training is comparable to sensory enriched environments and with the amount of variety in sensory, motor, and auditory experiences, the formation of new synapses, reformation, and connections becomes possible (Strait \& Kraus, 2014).

\section{Neuroplasticity and Learning in Musicians}

Since music training increases white matter, neuroplasticity, and the formation of new synapses, then we might expect musician's accuracy of learning a new task will be improved. Short-term memory and learning are thought to be strengths for musicians (Strait \& Kraus, 2014). Strait and Kraus argue that the cognitive sensitivity of attention and memory involving quick timing response, attention to tuning, and increased auditory sensitivity promotes synaptic plasticity and an overall advantage over nonmusicians.

Studying and learning to play music involves visual, auditory, motor, sensory, and memory training. Authors Anaya, Pisoni, and Kronenberger (2017) tested 24 musicians and 24 nonmusicians with the goal to assess visual-spatial learning and memory abilities in musicians. A total of four measures were used. The matrix reasoning was issued to provide "a normed baseline measure of global nonverbal intelligence," (Anaya, Pisoni, and Kronenberger, 2017, p. 5). The peabody picture vocabulary test IV (PPVT) was issued to examine receptive vocabulary skills. The digit span was delivered to measure "short-term auditory-verbal memory," (Anaya, Pisoni, and Kronenberger, 2017, p. 5). The visual-spatial sequence learning and memory was used to 
examine participant's ability to learn visual patterns. They found musicians performed better than nonmusicians. Musicians are constantly processing symbols, auditory, and sensory information in a short time period. Authors Anaya, Pisoni, and Kronenberger (2017), hypothesize that it is the years of formal musical training that benefit and enhance a musician's learning abilities. This study was similar to the learning assessment in comparing musicians and nonmusicians in the area of learning. However, the learning assessment remains a novel study in assessing accuracy of learning and RT in musicians and nonmusicians. The learning assessment used novel nonwords for the stimulus. The visual-spatial sequence learning and memory study consisted of learning shapes and sequences and also assessed vocabulary. Authors Anaya, Pisoni and Kronenberger state that future research should include musicians from a homogenous group in order to isolate features that may impact the result outcome. This is significant because there is still a lack of research regarding the relationship between music and the accuracy of learning and RT. The learning assessment studied woodwind musicians in order to isolate features.

\section{Auditory and Memory Tasks}

Musicians have increased auditory sensitivity that enables them to learn nonmusical structures more efficiently. This has been shown across musical ability levels and ages (Anand, Mohan, \& Yeraguntla, 2017; Carretti, Grassi, \& Talamini, 2016; Fauvel et. al 2014; Francois, 2011). Structural changes within the brain enables an increase in auditory evoked action potentials which allows for a larger neural representation for sounds (Francois 2011). A study conducted by Francois (2011), sought to answer if musical training improves artificial language learning. Participants included 16 professional musicians and 20 nonmusicians. The stimulus was 5.5 minutes of uninterrupted sung speech consisting of "5 3 -syllable nonsense words," (Francois 2011). Author Francois (2011), found that musicians have the ability to increase 
auditory information in short-term memory load compared to nonmusicians. It was found that musicians have a "larger representation for linguistic and musical structures during listening phases," (Francois 2011) and have the ability to organize sounds in sequence. Francois (2011) concludes that musicians have the ability to learn artificial language better than nonmusicians. This indicates that musicians may be able to learn novel nonwords better than nonmusicians due to their enhanced short term memory load, ability to organize sounds, and increase in auditory evoked action potentials.

A study by Talamini, Carretti, and Grassi (2016), was conducted to test musicians’ memory in a digit span test, which is a number memory task. Musicians and nonmusicians performed a digit span task that was presented auditorily, visually or both. Talamini, Carretti, and Grassi (2016) found that musicians had larger auditory and audiovisual spans. It was concluded that musicians have an advantage over nonmusicians in auditory working memory tasks.

Past studies have shown that musicians perform well in auditory tasks, even less experienced musicians (Anand, Mohan, \& Yeraguntla, 2017). School age children participated in musical training for 2 years and were compared to nonmusicians in an auditory processing task involving pitch and auditory perception. The new school age musicians performed better than the nonmusicians in the "pitch pattern test, the random gap detection test and in the child auditory processing performance scale," (Anand, Mohan, \& Yeraguntla, 2017, p. 1). The study concluded that music training improves auditory processing, which was seen in the school age children's classroom. This is important because the study demonstrates that music training can improve various processes, even for amateur musicians. 
It has been shown that even as musicians age, musicians outperform nonmusicians on working memory and auditory tasks. A study conducted by Fauvel et al. (2014) tested 68 musicians and nonmusicians. The mean age in the middle aged group of musicians and nonmusicians was 39 years and the mean age in the older group of musicians and nonmusicians was 76 years. Eight different experiments were conducted to test verbal long-term memory, auditory memory, processing speed, visual scanning, and non-verbal reasoning. The study found that musicians performed better than nonmusicians in processing speed and auditory memory for both age groups. Authors Fauvel et al. (2014), state music training involves "score reading, typing, and auditory attention," which increases neural responses for processing speed and auditory memory. This is significant because this provides musicians an advantage over nonmusicians in the area of cognitive aging. Though this study is similar to the learning assessment in the aspect of learning a task, this study sought to examine the effect of music training on cognitive aging. The learning assessment is comparing accuracy of learning and RT in musicians and nonmusicians.

All of these studies support the connection of musical training improving auditory sensitivity and memory. Structural change within the brain improves auditory function and allows an increase in information for short-term memory load for musicians. This is significant because it indicates musicians may perform better than nonmusicians in auditory based tasks. However, the relationship between the effect of music training on accuracy of learning in college age musicians remains unexplored.

\section{Relationship Between Memory and Increased Gray Matter}

Few authors (Kleber et al., 2016; \& Bermudez 2010) have explored the relationship between improved memory and increased gray matter in musicians. In testing 71 musicians and 
64 nonmusicians, Bermudez (2010) found that gray matter was significantly larger in musicians than nonmusicians. The musicians and nonmusicians were tested in a note naming task that sought to study memory using a brain scan to view areas of brain activation. While being subjected to the note naming task, the musician's' brain scan showed the posterior dorsolateral frontal, ventrolateral frontal and parietal areas activated. These areas of the brain are responsible for synapsing neurons and sending sensory information to different parts of the brain. This is significant because it shows that increased gray matter creates increased synapses therefore improving memory. Musicians working memory is highly developed due to "enhanced neural networks", increased gray matter and "white matter connectivity" (Loui, 2016).

An increase in gray matter has not only been shown in instrumental musicians but vocal musicians too (Kleber et al., 2016). This study sought to explore the relationship of "use dependent structural plasticity" in vocalists and gray matter. The study consisted of 27 professional classical singers and 28 participants with no trained signing experience. It was found gray matter increases in the "ventral primary somatosensory cortex and adjacent rostral supramarginal gyrus, as well as in secondary somatosensory and primary auditory cortices," in singers (Kleber et al., 2016). This is significant because it demonstrates that different forms of musical training can create structural changes in gray matter.

Previous research has shown a positive relationship between music training and an increase in neuroplasticity (Schmithorst \& Wilke, 2002), in gray matter and white matter (Gaser \& Schlaug, 2013), and an improvement in auditory sensitivity and memory (Anand, Mohan, \& Yeraguntla, 2017; Carretti, Grassi, \& Talamini, 2016; Fauvel et. al 2014; Francois, 2011). However, no previous studies have addressed the question: Does an adult musician learn more 
accurately than an adult nonmusician? That is, does the increase in gray matter in the motor and somatosensory regions lead to accuracy in learning new auditory information?

Studies have used novel nonwords (Kaushanskaya 2011) in order to test accuracy of learning. Author Kaushankaya (2011), sought to study the effect of bilingualism and monolingualism on word-learning. The stimuli were novel nonwords that presented similar to English phonemes. Nonwords are a good test of learning because they combine working memory and in the case of auditory nonwords, input of auditory information. Testing novel nonword learning can demonstrate learning of new information and the cognitive processes involved. Existing studies have not studied the effect of musical training on accuracy of learning. Nonwords will test whether auditory learning in musicians extends to accuracy of learning novel nonwords. Therefore, I tested nonword learning in musicians compared to nonmusicians. 


\section{RESEARCH QUESTION}

If myelination, synapses, and neurons are increased in musicians leading to better auditory learning, then do adult musicians learn nonwords more accurately than adult nonmusicians?

\section{METHODOLOGY}

\section{PARTICIPANTS}

Participants were 10 college age adults ( 5 female, 5 male), 20-26 years old recruited from the Portland State University community. The participants was divided into two groups: 5 musicians with 5-10 years of musical practice on a wind instrument and 5 nonmusicians with no musical practice in the last 5-10 years. Those with history of neurological or developmental disorders and hearing impairments will be excluded from the study. All methods were approved by the Portland State University Institutional Review Board.

\section{STIMULUS MATERIAL}

The stimuli were twelve novel nonwords that are phonetically similar to English words (Kaushanskaya 2011). The stimuli were chosen from http://elexicon.wustl.edu/NonWordStart.asp. All twelve nonwords were chosen at random and consisted of five letters, vowels, and consonants. The twelve nonwords were: aarod, ahack, abose, abape, abhar, faste, tathe, pasil, peads, reaut and hebop. There were twelve nonwords that participants were presented, however they were only tested on ten of the words leaving two outliers: Abape and Peads. Each word was associated with a picture (see Figure 1).

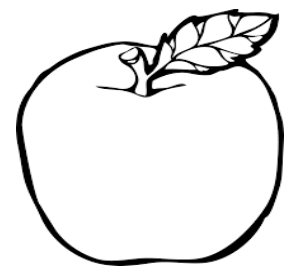

Figure 1. Example of stimuli. This figure illustrates an example of the word Pasil associated with a picture. 


\section{PROCEDURE}

Testing took place at Portland State University in the Neurolinguistics lab. Participants were tested individually during one session. The session took approximately an hour and consisted of two phases: a word learning and testing phase. Once participants signed the informed consent form, the experimental trials began. All participants were tested in a sound attenuated room with a computer and headphones. Consistent SPL was used for each participant at approximately 65 $\mathrm{dB}$. During the learning portion phase, the participant saw an instruction screen that read: "The learning portion will consist of twelve words. You will have four seconds to memorize one word. You will be shown a picture, a word, and hear an audio stimuli. After the learning portion, you will be directed to the testing portion." The objective was to learn that the picture was correlated with a nonword. Each word and photo were shown for four seconds (Harb 2010) while the participant heard the auditory word. After 4 seconds, a blank screen was displayed for one second (Nico 1985). After hearing all twelve words, participant was tested for accuracy of word learning. During the testing portion, the picture was shown on the screen, four words were in a word bank to chose from. During the testing phase, participants saw a new set of instructions that read: "Based on the picture shown, choose the word that goes with it as quickly as possible. When you are finished, you may exit the lab." Participants identified which word belongs to each picture by clicking on the appropriate word in the word bank with a computer mouse. Each participant was tested on the same ten words, leaving the same two outliers. 


\section{RESULTS}

Two independent t-tests were conducted to determine whether accuracy and reaction time (RT) differed between musicians and nonmusicians. Musicians did not differ significantly from nonmusicians; $\mathrm{t}(8)=1.234, \mathrm{p}=.252$ (one tailed). Musicians showed no significant difference in RTs compared to nonmusicians, $\mathrm{t}(8)=(0.542), \mathrm{p}=0.603$, (one tailed). Table 1 shows means and SDs for the dependent variables for each group.

Table 1

Comparison of Accuracy and RT between Musicians vs. Nonmusicians Musicians Nonmusicians

Accuracy Mean (SD) $\quad 88.00(13.04) \quad 72.00(25.88)$

RT Mean (SD) $\quad 3335.800(921.279) \quad 3699.980(1186.460)$

Table 1 Comparison of Accuracy and RT between Musicians and Nonmusicians

\section{DISCUSSION}

The main objective of this experiment was to compare the accuracy of learning between musicians and nonmusicians. With this objective, we tested 5 musicians and 5 nonmusicians on novel nonword learning. My hypothesis that adult musicians will learn nonwords more accurately than adult nonmusicians was not supported by this data because there were no difference in accuracy of learning or RTs between musicians and nonmusicians.

My findings are inconsistent with previous literature studies that report that musicians outperform nonmusicians in learning on various tasks (Francois, 2011; Strait \& Kraus, 2014). 
Memory and learning are widely accepted strengths for musicians (Francois, 2011; Strait \& Kraus, 2014). It is argued that the auditory sensitivity and memory involved in music training promotes synaptic plasticity and an overall advantage over nonmusicians (Strait \& Kraus 2014). Musicians have the ability to increase auditory information in short-term memory load compared to nonmusicians because musicians have the ability to organize sounds in sequence (Francois 2011), seemingly confirmed recently by Talamini, Carretti, \& Grassi, (2016) who found that musicians have an advantage over nonmusicians in working memory and auditory tasks.

The results of the current study do not confirm previous findings and arguments (Anaya, Pisoni, \& Kronenberger, 2017), but the current findings also do not provide strong evidence against previous research due to a few limitations. Limitations of our study included a small sample size, lack of musical proficiency level measurements, lack of controlling for sight reading (to perform a piece of music with no previous planning) experience in musicians, and lack of in depth background on type of instrumental expertise and experience.

Sample size effects result outcomes. The learning assessment sample size was small, 5 musicians and 5 nonmusicians. In statistics, it is important to have a large sample size in order to avoid committing a type II error, which states that the null hypothesis that was accepted was false. Landry and Champoux (2017) studied 35 participants reaction time, consisting of 16 musicians and 19 nonmusicians. They found that musicians reacted faster and found "statistical advantage from multisensory coactivation" (Landry \& Champoux 2017). They found that with an auditory stimuli, musicians had a faster reaction time. The relationship of a larger sample size is related to significant results in previous literature. As discussed in the introduction, a recent study (Anaya, Pisoni, \& Kronenberger, 2017) found that musicians performed better than nonmusicians in a visual-spatial learning and memory task. This was demonstrated testing 24 
musicians and 24 nonmusicians. Years of music training consists of musicians processing symbols, auditory, and sensory information in a short time period. This benefits and enhances a musician's learning abilities. Thus, the musicians and nonmusicians that participated in my study may have in fact been shown to be different with larger groups.

Years of experience on an instrument could impact result outcomes too. The participants in the current learning assessment had 5 or more years of experience on their instrument, which may have impacted the result outcome. The participants in the study conducted by Landry and Champoux (2017) had started playing their instruments between the age of 3 and 10 years. Most of the musician participants were in their Master's programs, leaving one undergraduate and one P.h.D. They had on average a total of at least 7 years of formal musical training, which is far greater than the musicians in the current learning assessment. Even though there are benefits in music training across the lifespan (Fauvel et. al, 2014), starting music training in childhood display better literacy and and a higher IQ (Fauvel et al., 2014). There is a significant relationship between starting music training at a young age during brain development and change in brain anatomy (Gaser \& Schlaug, 2013). The study by Fauvel et. al (2014) sought to explore the effect of musical training and different ages. It found that processing speed and auditory verbal short term memory tasks were performed better by musicians than nonmusicians for different age groups. However, the study also found that musicians who started musical training in childhood performed better in phonemic fluency tasks than musicians who started musical training in adulthood. As discussed in the introduction, this could be explained by the intensity of motor training and auditory sensitivity on a developing brain that increases the development of new neurons and enhance structural plasticity (Schmithorst \& Wilke, 2002). 
Differences in sight reading ability may have impacted the outcome of results. As discussed in the introduction, according to Gaylen (2005), there is a connection to good sight readers and academic achievement. However, being a good sight reader depends on the amount of experience in performing music, music training, and innate musical ability (Gaylen, 2005). However, self-report measures may not be as accurate as a more objective form of sight reading evaluation. Characteristics of a good sight reader are perception, kinesthetics, memory, and problem solving skills (Lehmann \& McArthur, 2002). There are many personal definitions of “sight-reading." One may consider themselves a good sight reader after one run through of a piece, or another may consider themselves a true sight reader after extensive personal practice on a series of new etudes (Lehmann \& McArthur, 2002). Thus, my participants may have had lower sight reading ability than musicians in previous studies resulting in my null outcome.

Different skills are acquired with musicians who are on the instrumental track and conductor track. Woodwind musicians on the instrumental track spend many hours on their specific instrument of focus and typically read one line of musical notes at a time. However, a conductor has to spend hours studying a musical score and composition, which has multiple lines of musical notes. An event-related brain potential study found that in comparing conductors to musicians and nonmusicians, only conductors responded to stimuli occurring in the "peripheral auditory space" and stimuli outside "the focus of spatial attention" (Münte, Nager, Beiss, Schroeder, \& Altenmüller, 2003). This is important because this shows that different types of musical training yield musicians to process and respond to different stimuli. Thus, the specific experience of the musicians in my study may have affected the outcome. 


\section{FUTURE RESEARCH}

Future research should include a brief questionnaire about different activities performed by musicians and nonmusicians because it may have interfered with the results. Structural brain changes were found with any motor or sensory skill learning such as sports, musicianship, or computer games (Fields 2011). However, the study states that white matter was increased in musicians compared to nonmusicians (Fields 2011). Different structures increase and decrease based on skill based activities. Future research should also include an extensive interview and a possible sight reading playing test to find similar sight reading ability. Type of musical participation should be included as this study could not be controlled for socioeconomic factors such as family income and parental education. If the parent had experience with music training, education, or varying forms of participation, the more likely their child will have years of private lessons, different forms of experiences, or musical training classes.

This design only took woodwind music background which limited the amount of possible variables. However, the design did not exclude musicians on the conductor track, therefore it did introduce a possible variable of different sensitivities for different stimuli. In the future, it will be important to study musicians who specialize in one instrument to decrease the amount of variables. Even though this study was not designed to study the relationship of musical expertise and heredity, it should be taken into account for future studies. Some studies have suggested that heredity has an affect on musical ability (Brown 2015).

In conclusion, the present study examined the relationship between musical training and accuracy of learning nonwords. No differences were found in accuracy of learning or RT's between musicians (individuals with 5 or more years of musical training experience) and nonmusicians (individuals with no musical training experience). The lack of difference in 
accuracy of learning and RT between musicians and nonmusicians do not confirm previous findings and arguments (Anaya, Pisoni, \& Kronenberger, 2017), but the current findings also do not provide strong evidence against previous research due to a few limitations. We suggest for future investigations to include a larger sample size, optimal musical proficiency level measurements, control for sight reading experience in musicians, and conduct an in depth background on type of instrumental expertise and experience. 


\section{References}

Anand, K., Mohan, K. M., \& Yeraguntla, K. (2017). Auditory processing abilities in amateur musicians [Abstract]. International Journal on Disability and Human Development, 16(1), 105-113. doi:http://dx.doi.org.proxy.lib.pdx.edu/10.1515/ijdhd-2016-0038

Anaya, E. M., Pisoni, D. B., \& Kronenberger, W. G. (2017). Visual-spatial sequence learning and memory in trained musicians. Psychology of Music, 45(1), 5-21. doi:http://dx.doi.org.proxy.lib.pdx.edu/10.1177/0305735616638942

Baker, F., Wigram, T., \& Gold, C. (2005). The effects of a song-singing programme on the affective speaking intonation of people with traumatic brain injury. Brain Injury, 19(7), 519-528. Retrieved from

http://stats.lib.pdx.edu/proxy.php?url=http://search.proquest.com.proxy.lib.pdx.edu/docvi ew/85619210?accountid=13265

Bednarek, E., \& Caroni, P. (2011). $\beta$-Adducin Is Required for Stable Assembly of New Synapses and Improved Memory upon Environmental Enrichment. Neuron, 69(6), 11321146. doi:10.1016/j.neuron.2011.02.034

Bengtsson, S. L., Nagy, Z., Skare, S., Forsman, L., Forssberg, H., \& Ullén, F. (2005). Extensive piano practicing has regionally specific effects on white matter development. Nature Neuroscience, 8(9), 1148-1150. doi:10.1038/nn1516

Bermudez, P. (2010). The neural correlates of absolute pitch (Order No. AAINR53300). Available from PsycINFO. (754057895; 2010-99120-040). Retrieved from http://stats.lib.pdx.edu/proxy.php?url=http://search.proquest.com.proxy.lib.pdx.edu/docvi ew/754057895? accountid=13265 
Brown, R. M., Zatorre, R. J., \& Penhune, V. B. (2015). Expert music performance: Cognitive, neural, and developmental bases. Progress in Brain Research, 217, 57-86.

Creech, A. (2008). Review of psychology for musicians: Understanding and acquiring the skills. Psychology of Music, 36(3), 383-386. doi:http://dx.doi.org/10.1177/0305735608093432

Dittinger, E., Barbaroux, M., D'Imperio, M., Jäncke, L., Elmer, S., \& Besson, M. (2016).

Professional music training and novel word learning: From faster semantic encoding to longer-lasting word representations. Journal of Cognitive Neuroscience, 28(10), 15841602. doi:http://dx.doi.org.proxy.lib.pdx.edu/10.1162/jocn_a_00997

Fauvel, B., Groussard, M., Mutlu, J., Arenaza-Urquijo, E., Eustache, F., Desgranges, B., \& Platel, H. (2014). Musical practice and cognitive aging: Two cross-sectional studies point to phonemic fluency as a potential candidate for a use-dependent adaptation. Frontiers in Aging Neuroscience, 6, 12. Retrieved from http://stats.lib.pdx.edu/proxy.php?url=http://search.proquest.com.proxy.lib.pdx.edu/docvi ew/1683364906? accountid=13265

Fields, R. D. (2011). Imaging Learning: The Search for a Memory Trace. The Neuroscientist, $17(2), 185-196$.

François, C., Grau-Sánchez, J., Duarte, E., \& Rodriguez-Fornells, A. (2015). Musical training as an alternative and effective method for neuro-education and neuro-rehabilitation. Frontiers in Psychology Front. Psychol., 6.

Francois, C., \& Schon, D. (2011). Musical Expertise Boosts Implicit Learning of Both Musical and Linguistic Structures. Cerebral Cortex, 21(10), 2357-2365.

Gaser and Schlaug, Brain Structures Differ between Musicians and Non-Musicians. (2013). Journal of Neuroscience, 33(36), 14629-14629. doi:10.1523/jneurosci.3403-13.2013 
Galyen, S. D. (2005, Fall-Winter). Sight-reading ability in wind and percussion students: a review of recent literature. Update: Applications of Research in Music Education, 24(1), $57+$. Retrieved from http://go.galegroup.com/ps/i.do?id=GALE\%7CA141170673\&v=2.1\&u=s1185784\&it=r $\& p=P P F A \& s w=w \& a s i d=49 b 9 e c d 0 c 3 a b 12414 f 7 c 898 b b 001 \mathrm{f} 8 \mathrm{~d} 3$

Kaushanskaya, M. (2012). Cognitive mechanisms of word learning in bilingual and monolingual adults: The role of phonological memory. Bilingualism, 15(3), 470-489. doi:http://dx.doi.org/10.1017/S1366728911000472

Kleber, B., Veit, R., Moll, C. V., Gaser, C., Birbaumer, N., \& Lotze, M. (2016). Voxel-based morphometry in opera singers: Increased gray-matter volume in right somatosensory and auditory cortices. NeuroImage, 133, 477-483. doi:http://dx.doi.org.proxy.lib.pdx.edu/10.1016/j.neuroimage.2016.03.045

Landry, S. P., \& Champoux, F. (2017). Musicians react faster and are better multisensory integrators. Brain and Cognition, 111, 156-162. doi:http://dx.doi.org.proxy.lib.pdx.edu/10.1016/j.bandc.2016.12.001

Lehmann, A. C., and McArthur, V. (2002). “Sight-Reading,” in The Science And Psychology Of Music Performance: Creative Strategies For Teaching And Learning, eds R. Parncutt and G. McPherson (Oxford: Oxford University Press).

Leśniewska, J., \& Pichette, F. (2016). Songs vs. stories: Impact of input sources on ESL vocabulary acquisition by preliterate children. International Journal of Bilingual Education and Bilingualism, 19(1), 18-34.

doi:http://dx.doi.org/10.1080/13670050.2014.960360 
Loui, P. (2016). Absolute pitch. In S. Hallam, I. Cross \& M. Thaut (Eds.), 2nd ed.; the oxford handbook of music psychology (2nd ed.) (2nd ed. ed., pp. 81-94, Chapter xv, 950 Pages) Oxford University Press, New York, NY. Retrieved from http://stats.lib.pdx.edu/proxy.php?url=http://search.proquest.com.proxy.lib.pdx.edu/docvi ew/1790932156? accountid=13265

Münte, T. F., Nager, W., Beiss, T., Schroeder, C., \& Altenmüller, E. (2003). Specialization of the specialized: Electrophysiological investigations in professional musicians. Paper presented at the 131-139, Chapter xii, 548 Pages. Retrieved from http://stats.lib.pdx.edu/proxy.php?url=http://search.proquest.com.proxy.lib.pdx.edu/docvi ew/620283659? accountid=1326

Newton, H. B. (2015). The neurology of creativity: Focus on music. In C. Charyton (Ed.), Creativity and innovation among science and art: A discussion of the two cultures; creativity and innovation among science and art: A discussion of the two cultures (pp. 352, Chapter xvii, 239 Pages) Springer-Verlag Publishing, New York, NY. doi:http://dx.doi.org.proxy.lib.pdx.edu/10.1007/978-1-4471-6624-5_2

Oechslin, M. S., Descloux, C., Croquelois, A., Chanal, J., Van De Ville, D., Lazeyras, F. and James, C. E. (2013), Hippocampal volume predicts fluid intelligence in musically trained people. Hippocampus, 23: 552-558. doi:10.1002/hipo.22120

Proverbio, A. M., Manfredi, M., Zani, A., \& Adorni, R. (2013). Musical expertise affects neural bases of letter recognition. Neuropsychologia, 51(3), 538-549. Retrieved from http://stats.lib.pdx.edu/proxy.php?url=http://search.proquest.com/docview/1417554567?a ccountid $=13265$ 
Roembke, T. C., \& McMurray, B. (2016). Observational word learning: Beyond propose-butverify and associative bean counting. Journal of Memory and Language, 87, 105-127. doi:http://dx.doi.org/10.1016/j.jml.2015.09.005

Sacks, O. (2007). Speech and Song: Aphasia and Music Therapy. In Musicophilia(pp. 214-223). New York: Alfred A. Knopf.

Schön, D., Anton, J. L., Roth, M., \& Besson, M. (2002). An fMRI study of music sight-reading. Neuroreport, 13(17), 2285-2289.

Schmithorst, V. J., Wilke, M., (2002). Differences in white matter architecture between musicians and non-musicians: a diffusion tensor imaging study. Neuroscience Letters, 321, Issues 1-2, 15, 57-60. http://dx.doi.org/10.1016/S0304-3940(02)00054-X.

Siw G. Nielsen (1999). Learning strategies in instrumental music practice. British Journal of Music Education, 16, pp 275-291.

Shadmehr R. and Holcomb HH, Neural correlates of motor memory consolidation, Science, 277 (1997) 821-825.

Strait, D. L., Kraus, N., (2014). Biological impact of auditory expertise across the lifespan: Musicians as a model of auditory learning, Hearing Research, 308, 109-121. http://dx.doi.org/10.1016/j.heares.2013.08.004.

Talamini, F., Carretti, B., \& Grassi, M. (2016). The working memory of musicians and nonmusicians. Music Perception, 34(2), 183-191. doi:http://dx.doi.org.proxy.lib.pdx.edu/10.1525/mp.2016.34.2.183

Tierney, A., \& Kraus, N. (2013). The ability to move to a beat is linked to the consistency of neural responses to sound. The Journal of Neuroscience, 33(38), 14981-14988. doi:http://dx.doi.org/10.1523/JNEUROSCI.0612-13.2013 
Wan, C. Y., \& Schlaug, G. (2010). Music Making as a Tool for Promoting Brain Plasticity across the Life Span. The Neuroscientist : A Review Journal Bringing Neurobiology, Neurology and Psychiatry, 16(5), 566-577. http://doi.org/10.1177/1073858410377805 